\title{
A DEMOCRACIA DO HOMEM COMUM: RESGATANDO A TEORIA POLÍTICA DE JOHN DEWEY
}

\author{
Thamy Pogrebinschi
}

\begin{abstract}
RESUMO
Entre os principais assuntos que vêm marcando presença na agenda da teoria política contemporânea nos últimos anos, estão os temas da deliberação, da comunidade e da comunicação. O que os "novos" debates sobre a democracia deliberativa, o comunitarismo e a teoria da comunicação não deixam claro, contudo, consiste no fato de que a "novidade" que apresentam já se encontrava anunciada na teoria pragmatista desenvolvida no começo do século XX, especialmente nos escritos de John Dewey. Com efeito, nos primeiros anos desse século, Dewey elaborou uma consistente teoria política normativa, cujo principal foco centravase na questão da democracia. Isso não teria nenhuma relevância especial caso a teoria democrática avançada por Dewey não abarcasse efetivamente uma concepção normativa de democracia participativa ou deliberativa nos mesmos moldes discutidos pelas mais recentes tendências e autores da teoria democrática contemporânea. A partir da leitura de Dewey e de alguns de seus comentadores, é possível identificar um conceito de democracia "radical", "procedimental" $e$ "deliberativa" que apresenta fortes ressonâncias, por exemplo, com os temas de comunidade, participação, comunicação, espaço público e educação. Diante disso, o objetivo deste artigo consiste em recuperar o pensamento de John Dewey, demonstrando o seu vanguardismo frente à teoria política contemporânea e indicando a relevância de sua contribuição para o atual debate da teoria da democracia.
\end{abstract}

PALAVRAS-CHAVE: democracia; homem comum; teoria política; John Dewey.

"Regarded as an idea, democracy is not an alternative to other principles of associated life. It is the idea of community life itself"

John Dewey (1927, p. 148) ${ }^{1}$.

\section{INTRODUÇÃO}

O nome de John Dewey é usualmente associado à Filosofia da Educação ou ainda à Psicologia e à Ética, tendo sido por longo tempo conhecido e estudado apenas nos domínios restritos da Filosofia ou da Pedagogia. Com a revivescência do pragmatismo nos últimos 20 anos e o conseqüente surgimento daquilo que se passou a chamar de neopragmatismo, o pensamento de Dewey começou a ser recuperado em sua integridade, transpondo assim as barreiras das disciplinas acadêmicas e fazendo-se ouvir também no campo das $\mathrm{Ci}$ ências Sociais. Com efeito, é no âmbito das Ciências Sociais e, especialmente, da Teoria Política que o pensamento de Dewey encontra sua maior potencialidade de aplicação e inovação. Conforme tentaremos argumentar neste artigo, a teoria política desenvolvida por John Dewey no começo do século XX é perfeitamente condizente com a atual agenda da Teoria Política contemporânea. De fato, Dewey antecipou em várias décadas os recentes debates em torno, por exemplo, do comunitarismo e das formas deliberativa e procedimental da democracia. Nesse sentido, o pragmatismo político de Dewey é ainda extremamente atual e inovador e apresenta infinitas possibilidades de contribuição para os debates contemporâneos ${ }^{2}$.

Conforme acreditamos ficar claro nas páginas que se seguem, Dewey possui efetivamente uma teoria do Estado e uma teoria da democracia. Os principais temas que orientam seu pensamento po-

\footnotetext{
1 No original: "Encarada como uma idéia, a democracia não é uma alternativa a outros princípios de vida associativa. Ela é a própria idéia de vida em comunidade". Todos os trechos originalmente em inglês foram traduzidos pela autora.

2 Sobre a atualidade do pensamento de Dewey e suas relações com a Teoria Política contemporânea, veja-se: Ryan (1995, p. 23, 36), Festenstein (1997, p. 9) e Bernstein (1998, p. 151-153).
} 
lítico, com efeito, são os temas da comunidade e da democracia. Como já nos indica Dewey na epígrafe deste artigo, ambos os temas estão demasiada e inevitavelmente conectados, sendo muito difícil, portanto, tratá-los como duas categorias separadas. No entanto, neste artigo trataremos apenas do conceito de democracia, fazendo algumas referências ao conceito de comunidade apenas quando isso nos parecer inevitável - apesar de que, como veremos, a compreensão de um implica necessariamente a compreensão do outro.

As idéias de Dewey acerca da democracia surpreendem pela sua atualidade. Diante disso, o que pode ser chamado de neopragmatismo na Teoria Política vem-se formando muito mais a partir de um resgate das idéias de Dewey do que propriamente por meio da elaboração de novos argumentos sobre o assunto. Com efeito, há, nos últimos anos, um número crescente de estudiosos que se preocupam com a discussão crítica e a interpretação dos escritos de Dewey. É nesse sentido, portanto, que podemos propriamente falar de um neopragmatismo político: no sentido de uma reatualização das idéias desenvolvidas inicialmente por Dewey na primeira metade do século XX. Dessas idéias, ao lado do conceito de comunidade, a democracia é sem dúvida a principal.

\section{A DEMOCRACIA COMO IDÉIA}

Para entender o conceito de democracia de Dewey é preciso partir de uma distinção por ele mesmo operada. Trata-se, por um lado, de distinguir a democracia como uma idéia e, por outro lado, como um sistema de governo. À democracia enquanto um sistema de governo Dewey chama de democracia política. Mas é com a "idéia de democracia" que Dewey está mais preocupado, ainda que os dois conceitos estejam conectados. Contudo, é possível perceber facilmente na essência do pensamento deweyano as linhas definidoras de cada uma dessas duas frações do conceito de democracia e será com base nelas que orientaremos nossa exposição a partir de agora.

A democracia como uma idéia (social ou moral, conforme Dewey acrescenta indistintamente) consiste na abordagem do conceito de democracia que foi quantitativa e qualitativamente mais desenvolvido por Dewey e também aquele a cujo respeito ele parecia preferir escrever e pensar. Trata-se essa idéia de acreditar que a democracia é um modo de vida. Mas, antes de anteciparmos a essência do conceito de democracia enquanto uma idéia, é preciso ir por partes, reconstruindo a trajetória da formulação desse conceito no pensamento de seu autor.

A idéia de democracia é tão vasta e tão plena que, de acordo com Dewey, não pode ser exemplificada por meio do Estado. Nenhum Estado, nenhuma forma de Estado, por melhor que seja, é suficiente para exemplificar a idéia de democracia em sua integridade. Isso porque a democracia, a sua realização, transcende o Estado: ela encontra-se, simultaneamente, em todos os modos de associação humana dentro da comunidade, afetando-os reciprocamente. Para que a idéia de democracia seja realizada, em conseqüência, ela precisa produzir efeitos sobre a família, a escola, a religião, o trabalho ("industry", no sentido mais amplo que a tradução não confere), além de outras formas de associação humana. Nesse sentido, a "democracia política" - isto é, a democracia como um sistema de governo - com seus arranjos políticos e instituições governamentais consiste meramente em um mecanismo destinado a assegurar canais de operação para a "idéia" de democracia. Diante disso, as críticas, as desaprovações e mesmo as modificações da "maquinaria" da democracia política não afetam a "idéia", que permanece sempre intocável. Em outras palavras, a democracia enquanto forma de governo, ou seja, a "democracia política", pode a qualquer momento ser revista, modificada, sem que isso afete a idéia de democracia. Isso porque a "idéia" sempre encontrará uma maquinaria política mais adequada para, por meio dela, continuar funcionando ${ }^{3}$.

A primeira lição da teoria democrática de Dewey, portanto, é não confundir, e jamais identificar, a "idéia de democracia" com os seus "órgãos e estruturas externas". Ao passo que a idéia de democracia é inabalável, suas "formas políticas" estão sujeitas a críticas e crises constantes. Disso decorre, afirma Dewey, ser um erro repetir o velho bordão que afirma que o remédio para os males da democracia é mais democracia. Afinal,

\footnotetext{
3 Observe-se como aqui operam claramente o contextualismo e o conseqüencialismo característicos do pragmatismo de Dewey. A "democracia política" adaptase continuamente ao seu contexto e ao seu fim, em ambos os casos a "idéia de democracia".
} 
se os males vêm a ser remediados por meio da adição do mesmo tipo de "maquinaria" (leia-se instituições e arranjos políticos) já existente ou mesmo por meio do aperfeiçoamento ou refinamento daquela maquinaria, a democracia permanece doente, passível dos mesmos males. A cura para uma democracia em crise, diz Dewey, apenas pode ser alcançada se ao velho bordão for conferido um outro sentido, qual seja, o de retornar à própria "idéia" de democracia. A solução para os males da democracia política reside, assim, em encontrar a substância da "idéia", em clarificá-la, compreendê-la, apreendê-la em seu sentido mais profundo, de modo a então possibilitar a crítica e a reconstrução de suas "manifestações políticas" (DEWEY, 1927, p. 143-144).

De acordo com o autor, é um erro considerar que foi a "idéia de democracia" por si mesma que produziu as práticas governamentais encontráveis nos estados democráticos, isto é, o sufrágio, a representação, a regra da maioria, entre outras. A "idéia" apenas influenciou movimentos políticos concretos que resultaram nessas práticas, mas não as causou. Em outras palavras, as formas assumidas pela "democracia política" ao longo do tempo, bem como as formas que se encontram consolidadas atualmente, representam o efeito cumulativo de inúmeros eventos de ordem histórica e não foram simplesmente determinadas pela "idéia" de democracia. Assim, explica Dewey, a intenção que levou à criação das conhecidas instituições da democracia moderna foi a de satisfazer necessidades e demandas concretas e não a de promover a "idéia" democrática.

Destarte, considerar que o governo existe para servir sua comunidade e que seus propósitos apenas são alcançados quando a própria comunidade participa da escolha de seus governantes e da determinação das políticas por eles implementadas é pouco para Dewey. Isso corresponde apenas a uma parte da idéia democrática, sua "fase política". Dewey está certo de que qualquer modificação que venha a ser implementada na "maquinaria democrática" existente deverá fazer que os interesses do público ("the public") constituam-se cada vez mais como os critérios e parâmetros da atividade governamental, de modo que ele, o público, possa formar e manifestar seus propósitos de forma cada vez mais decisiva. Dewey está certo também de que muitas sugestões de reforma e melhoria da "forma política da democracia" são e serão - permanentemente discutidas. Por isso é que ele acredita que o seu papel não deve ser o de engrossar esse rol, mas o de discutir as questões mais profundas que estão por trás dele. Essas questões, que segundo ele configuram um problema intelectual e não político, consistem em tentar descobrir os meios pelos quais o público pode reconhecer a si mesmo de modo a definir e expressar seus próprios interesses (idem, p. 145-146).

$\mathrm{Na}$ busca das condições por meio das quais o público pode funcionar democraticamente, é preciso ir ao encontro do tema da comunidade e aos problemas a ele relativos. Esses, afinal, são os problemas que Dewey quer enfrentar, ao contrário de se preocupar em sugerir aperfeiçoamentos para os governos democráticos - até porque, enquanto a "Grande Sociedade" não se converter em "Grande Comunidade", "é de certo modo fútil considerar qual maquinaria política irá servi-la" (idem, p. $147)^{4}$. "No exame das condições sob as quais o público disforme agora existente pode funcionar democraticamente, devemos proceder a partir de uma proposição da natureza da idéia democrática

\footnotetext{
${ }^{4}$ Conforme mostramos em outro lugar (POGREBINSCHI, 2002), o objetivo de Dewey em seu livro The Public and its Problems é duplo. Ele quer, por um lado, compreender como a era industrial, ao desenvolver a Grande Sociedade (Great Society), invalidou e desintegrou as comunidades pequenas dos tempos passados sem gerar uma "Grande Comunidade". Além disso, ele quer que o público descubra a sua própria identidade, saindo do eclipse em que se encontra. O desafio de Dewey naquele livro portanto, é o de investigar as condições a partir das quais a Grande Sociedade pode converter-se em uma Grande Comunidade. Lembramos que o conceito de "Grande Sociedade" foi criado pelo teórico político britânico Graham Wallas, amigo de Walter Lippmann, que, por sua vez, era um grande adversário intelectual de Dewey. Esse conceito implica a idéia de que as sociedades industriais modernas são crescentemente abstratas e impessoais, bem como crescentemente privam seus membros de entenderem-se uns com os outros por meio de um contato pessoal em comunidades de pequena escala. O conceito de "Grande Comunidade" que Dewey cria para contrapor-se ao conceito de Wallas insiste exatamente na direção oposta, qual seja, na afirmação de que as sociedades industriais precisam ser recriadas a partir da experiência das pequenas comunidades locais, em que o contato humano dá-se face-aface. Assim como o conceito de democracia, de que estamos ora tratando, o conceito deweyano de comunidade consiste antes em uma concepção idealizada de vida comunal, isto é, em um certo modo de vida a ser perseguido como um ideal ético ou moral. Conforme ficará claro nas próximas páginas, a democracia para Dewey possui os mesmos pressupostos que a comunidade, quais sejam, a participação, a educação e a comunicação.
} 
em seu sentido social genérico. Do ponto de vista do indivíduo, isso consiste em ter uma parcela de responsabilidade de acordo com a capacidade de formar e dirigir as atividades dos grupos a que se pertence e em participar de acordo com a necessidade dos valores sustentados pelo grupo. Do ponto de vista dos grupos, isso demanda liberação das potencialidades dos seus membros em harmonia com os interesses e bens que são comuns. Uma vez que todo indivíduo é membro de vários grupos, essa especificação só pode ser cumprida se grupos diferentes interagirem flexível e plenamente em conexão com outros grupos. [...] Um bom cidadão considera a sua conduta como membro de um grupo político enriquecedora e enriquecida pela sua participação na vida familiar, no trabalho e nas associações científicas e artísticas" (idem, p. 147-148).

É nesse ponto, portanto, que os conceitos de democracia e comunidade encontram-se definitivamente. Encarada como uma idéia, conforme diznos Dewey na epígrafe deste artigo, a democracia não é uma alternativa a outros princípios de vida associativa, mas é a própria idéia de comunidade. Em suma, a idéia de democracia consiste em um ideal - um ideal de uma comunidade levada ao seu último limite; uma comunidade completa, perfeita: "A pura consciência de uma vida comunal, com todas as suas implicações, constitui a idéia de democracia" (idem, p. 149).

De acordo com Dewey, em conseqüência, uma idéia de democracia só não é uma idéia utópica quando se toma como ponto de partida a comunidade, ou melhor, o fato da comunidade, com todos os seus elementos constitutivos. Diante disso, Dewey acredita que todas as concepções tradicionalmente associadas à idéia de democracia apenas adquirem sentido e eficácia verdadeira quando estão vinculadas a uma comunidade real. Desse modo, por exemplo, o famoso lema revolucionário francês que clama por "liberdade, igualdade e fraternidade" precisa realizar-se na vida comunal, sem o que ele consistiria em mera abstração ineficaz. Assim, apenas quando está associada à comunidade, a liberdade consiste na "liberação e satisfação das potencialidades pessoais"; a igualdade, por sua vez, implica o "compartilhamento das conseqüências da ação coletiva" por parte de cada indivíduo membro da comunidade e, por fim, a fraternidade passa a ser "outro nome para os bens conscientemente apreciados" que provêm da própria associação e por ela são compartilhados (idem, p. 150) .

O que há de essencial, em conseqüência, nesse modo como Dewey encara a democracia, vale dizer, em sua concepção de democracia como idéia, é que ela deixa de ser vinculada unicamente à política. A política passa a ser apenas um dos lugares, um dos momentos, uma das formas que assume a democracia. Quando não está revestida de sua "forma política", portanto, a democracia é muito mais ampla: ela apresenta-se como uma idéia que espalha seus efeitos de múltiplas formas, em vários lugares ao mesmo tempo. Mas, de certa forma, podemos dizer que essa multiplicidade de expressões da democracia concentra-se em um lugar: na comunidade. "A democracia precisa começar em casa e sua casa é a comunidade vicinal [neighborly]" (idem, p. 213). É na comunidade, afinal, que se encontram os indivíduos, os grupos, as famílias, as escolas, as fábricas, as igrejas, as associações de caráter científico e artístico, enfim, todas as formas de associação humana. É na comunidade que os indivíduos e os grupos podem comunicar-se, interagindo uns com os outros, compartilhando suas atividades e conseqüências. Diante disso, talvez possamos afirmar que, para Dewey, a democracia encontra-se mais no social que no político - mesmo porque este último plano só deve vir à tona quando o público descobrir-se e isso somente pode acontecer por meio do social.

\section{DEMOCRACIA E AUTOGOVERNO: UMA PERSPECTIVA VANGUARDISTA?}

A democracia, portanto, é a solidificação das possibilidades inerentes à vida comunitária, social; é um todo único em que se incluem as potencialidades e as capacidades dos indivíduos que são desenvolvidas por meio de atividades cooperativas levadas a cabo pela comunidade. Contudo, se a democracia é uma forma de vida comunal que oferece oportunidades intermináveis para o desenvolvimento da individualidade em sua plenitude, é preciso que os indivíduos possam

\footnotetext{
5 Compare-se essas idéias com "Philosophy and Democracy" (1919), em que Dewey refere-se novamente aos ideais revolucionários como abstrações quando dissociados da vida comunitária, conferindo um conteúdo inteiramente pragmatista às idéias de liberdade e igualdade, retirando delas todo aspecto metafísico, idealista ou fundacionalista.
} 
participar da direção das suas vidas e da vida da comunidade em que estão inseridos. Os indivíduos membros das comunidades, portanto, devem participar da formação dos valores individuais e sociais que regulam sua vida comum. Em conseqüência, na medida em que a idéia de democracia engloba essa noção de auto-realização, ou seja, de constituição e consolidação recíprocas da individualidade e da coletividade uma por meio da outra, estabelece-se uma espécie de autogoverno.

Quando a auto-realização individual converte-se em autogoverno, a comunidade converte-se em uma democracia participativa. Com efeito, a idéia de democracia expressa-se na participação do indivíduo em todos os momentos e lugares da vida comunal, de que a esfera propriamente política representa apenas um aspecto. Ao lado de todas as suas funções enquanto membros da comunidade, os indivíduos possuem uma função especificamente política, qual seja, a de participar de maneira "direta" e "ativa" na regulação dos termos da vida associativa e na busca do bem comum. Entenda-se por regulação a participação na formulação, na definição e na implementação de políticas públicas. Por políticas públicas, por sua vez, entendam-se políticas que de fato constituem as necessidades e os interesses do público, as necessidades e interesses "comuns" no sentido de serem necessidades e interesses da comunidade. Desse modo, o governo e suas instituições constituem apenas uma das várias atividades associativas da comunidade. Os cidadãos deweyanos não precisam de um governo que não seja o deles próprios, a ser exercido de maneira direta e constante seja em casa, na escola, no trabalho, nas inúmeras associações com seus múltiplos fins: a democracia faz-se a si mesma em toda parte ${ }^{6}$.

Ao sustentar isso que inequivocamente é uma forma de democracia direta, Dewey não abre mão da idéia de representação, mas confere a ela um outro significado, uma outra compreensão, distinta daquela que estamos tradicionalmente acostumados a pensar. De acordo com ele, "nós comumente falamos de alguns governos como representativos

\footnotetext{
6 As semelhanças com o conceito de "espaço público" desenvolvidos no final do século XX por Hannah Arendt e Jürgen Habermas são aqui evidentes. É lastimável, contudo, que não se encontre na obra desses dois autores nenhuma análise ou menção à contribuição de Dewey.
}

em contraste com outros que não o são. Pela nossa hipótese, todos os governos são representativos" (idem, p. 76). O que faz que todos os governos sejam necessariamente representativos é que eles pretendem manter os interesses do público no comportamento dos indivíduos e dos grupos ${ }^{7}$. Um governo apenas é representativo quando o público está definitivamente organizado em sua intenção de assegurar o predomínio da prosperidade pública sobre quaisquer outros desejos que cada membro individual da comunidade tenha em seus papéis e ações não-políticas. Nesse sentido, todos os indivíduos possuem uma "capacidade dual": uma enquanto membro do governo e outra enquanto aquele que o elege. Potencialmente, todos podem ocupar essas duas posições e trabalhar para que o bem-estar do público prevaleça, assim como fazem em outras atividades associativas da comunidade que não o governo. Em tese, portanto, todos os governos são de fato representativos - e essa afirmação de Dewey não é nem um pouco contraditória no contexto de uma teoria da democracia que considera as instituições governamentais tão ou menos importantes que os demais desdobramentos da vida comunal.

A necessidade de participação para a constituição da comunidade e a absoluta indissociabilidade entre participação e democracia e entre esta e a comunidade leva-nos a supor que Dewey efetivamente antecipou em várias décadas algumas das recentes discussões da Teoria Política contemporânea em torno das idéias de participação, cidadania participativa e democracia participativa. Nesse sentido, o testemunho de Westbrook logo em uma das primeiras páginas de sua biografia intelectual de Dewey é valioso: "Entre os intelectuais liberais do século XX, Dewey foi o mais importante defensor da democracia participativa, isto é, a crença de que a democracia como um ideal ético clama que os homens e as mulheres construam comunidades em que as oportunidades e os recursos necessários estão disponíveis para cada

\footnotetext{
7 Observe-se que o que Dewey chama de "interesses e necessidades do público" ou "interesses e necessidades comuns" não poderia jamais ser identificado com a vontade geral rosseauniana, que, segundo Dewey, "com a influência da metafísica alemã, foi erigida no dogma de uma vontade absoluta mística e transcendente, a qual por sua vez apenas não é outro nome para força porque foi identificada com razão absoluta" (DEWEY, 1927, p. 54).
} 
indivíduo realizar plenamente suas capacidades e poderes particulares por meio da participação na vida política, social e cultural" (WESTBROOK, 1991, p. xiv-xv).

Essa idéia de democracia que promove, simultaneamente, a individualidade e o bem comum por meio de uma participação que não é meramente política, mas é, antes de tudo, social, faz de Dewey, conforme acreditamos, um dos precursores do tema da participação na Teoria Política. O que levou Dewey a elaborar uma teoria da democracia - sem dúvida normativa, ressalte-se - como esta, foi o seu desejo de opor-se às concepções realistas de democracia vigentes no seu tempo que sustentavam uma versão elitista dela. Muito antes de Joseph Schumpeter, a quem os novos teóricos da democracia vieram a opor-se nas últimas décadas do século XX, Dewey opunha-se no começo desse mesmo século ao elitismo democrático de autores como Walter Lippmann e Graham Wallas ${ }^{8}$.

A verdade é que a concepção de democracia avançada por Dewey corresponde em grande medida àquilo que Teoria Política contemporânea vem denominando de "democracia deliberativa". Com efeito, o próprio Westbrook afirmou recentemente que se este termo já estivesse tão em voga enquanto ele estava escrevendo sua conceituada biografia de Dewey, ele teria preferido usá-lo ao invés de "democracia participativa" (WESTBROOK, 1998, p. 138). O fato é que, conforme argumentamos em discussão específica sobre o conceito de comunidade (POGREBINSCHI, 2002, p. 108-132), além da participação, há outra noção igualmente essencial para Dewey, qual seja, a de comunicação. Além disso, o que torna a expressão "democracia deliberativa" a mais adequada, ao invés de "democracia participativa" ou ainda "democracia direta", é o fato de que Dewey não abdica absolutamente, como vimos, das instituições representativas.

Com efeito, a teoria da democracia deweyana funciona combinando características das formas direta e representativa de democracia, mas o que

8 Cf. Graham Wallas, The Great Society (1914); Walter Lippmann, Public Opinion (1997 [1922]) e The Phanton Public (1993 [1925]) - este último livro foi o que moveu definitivamente Dewey a publicar em 1927 o seu The Public and Its Problems, partindo do mesmo diagnóstico que os seus dois opositores, porém encaminhando-se a uma direção completamente oposta, como resta evidente. é imprescindível nas últimas é que elas internamente funcionem de modo inteiramente deliberativo. "O ponto mais forte a ser feito mesmo em favor de tais formas políticas rudimentares que a democracia já alcançou, o voto popular, a regra da maioria e assim por diante, é que em alguma medida elas envolvem uma consulta e uma discussão que revelam as necessidades e os problemas sociais" (DEWEY, 1927, p. 206; sem grifos no original).

Assim, de acordo com Dewey, o que faz que o sistema eleitoral com a sua regra de maioria não seja uma insensatez absoluta é que, para que a maioria seja alcançada, por exemplo, faz-se necessário todo um processo de "discussão", "consulta" e "persuasão". Vale dizer, as instituições representativas não podem prescindir de um certo grau de deliberação interna - sua maior (ou única) virtude segundo Dewey. E já que, por uma questão de lógica, não existem governos que não sejam representativos, aquela fração política da vida associativa que se chama governo deve, necessariamente, ser minimamente deliberativa em seu interior.

Quanto aos problemas da "democracia política" que Dewey abstém-se de discutir porque considera mais prementes as questões atinentes à "idéia de democracia", podemos encontrar no presente contexto de nossa análise uma indicação de sua posição sobre o assunto. Se o remédio para os males da democracia não é mais "democracia política" e sim mais "idéia de democracia", todavia, certamente Dewey concorda que a "maquinaria política" existente seria aperfeiçoada se aperfeiçoados fossem também os procedimentos de deliberação que dela fazem parte. A necessidade essencial, esclarece ele, "é o aperfeiçoamento dos métodos e condições de debate, discussão e persuasão. Esse é $o$ problema do público" (idem, p. 208; grifo no original). E esse é também $o$ problema da democracia.

O que há de mais inquietante no desvelamento dessa parte da teoria da democracia de Dewey, contudo, é a percepção de que todo o debate atual em torno da idéia de deliberação que vem ocupando o centro da agenda da Teoria Política contemporânea nos últimos anos resolutamente ignora a contribuição de Dewey sobre o assunto. É de saltar aos olhos o fato de que praticamente nenhum autor contemporâneo faça menção expressa a Dewey em suas postulações em prol de uma 
democracia deliberativa. Conforme dizem James Bohman e William Rehg na introdução de uma das principais coletâneas sobre o tema, por eles editada em 1997, "até a metade deste século [século XX], as teorias da democracia eram geralmente suspeitosas quanto à deliberação pública" (BOHMAN \& REHG, 1997b, p. x). Ora, se para eles as teorias elitistas só passaram a existir com Schumpeter, não é de surpreender que achem também que a idéia de deliberação surgiu apenas a partir da década de 1980. Com efeito, segundo acreditam esses dois teóricos políticos da contemporaneidade, a idéia de democracia deliberativa apareceu pela primeira vez em um artigo de Joseph Bessette, publicado em 1980 - e a partir daí "sua provocação uniu o coro de vozes clamando por uma visão participativa da política democrática" (idem, p. xii) ${ }^{9}$.

Sem dúvida, conforme já mencionamos antes, a concepção de democracia de Dewey é uma concepção normativa. Aliás, a Teoria Política pragmatista como um todo que pode ser inferida de Dewey também se antecipa nesse caráter normativo, estando ainda a oferecer, em conseqüência, inúmeras contribuições para a teoria normativa contemporânea ainda em processo de construção (FESTENSTEIN, 1997). Outro argumento que ainda desejamos ressaltar é que, em alguma medida, Dewey parece também antecipar um certo procedimentalismo em sua teoria democrática. Vale dizer, ao sustentar que a democracia deve ser exercida deliberativamente no seio das múltiplas formas associativas da sociedade, incluindo-se entre estas o governo e as instituições propriamente políticas, Dewey não especifica um

\footnotetext{
9 Alguns dos principais autores sobre democracia deliberativa e participativa que ignoram o pragmatismo político e a contribuição de Dewey são, entre outros além dos próprios Bohman e Rehg: Jon Elster, Joshua Cohen, Frank Michelman, David Held e James Fishkin. O próprio Habermas, apesar de mostrar-se um bom conhecedor do pragmatismo social de Mead e Peirce, jamais demonstrou expressamente ser um leitor de Dewey e tampouco se referiu de maneira efetiva à sua teoria da democracia ao desenvolver seus conceitos de "espaço público", "deliberação" e "democracia procedimental". Como aponta Robert Westbrook nesse sentido, as duas únicas exceções, ou seja, os dois únicos autores que parecem vincular mais claramente suas concepções de democracia deliberativa com Dewey são William Sullivan e Benjamin Barber (cf. WESTBROOK, 1991, p. 550).
}

determinado conteúdo substantivo constitutivo da idéia de democracia. Ou seja, a democracia deweyana, além de não se expressar pelas tradicionais vias do poder ou do interesse, não está tampouco contida na concretização, por exemplo, dos tradicionais ideais da liberdade ou mesmo da igualdade, assim como também não visa à materialização de um sistema de direitos. Se isso nos serve de argumento para afastar o pragmatismo político de Dewey do liberalismo, também nos serve para indicar uma certa antecipação do procedimentalismo, mas com uma diferença importante: ao contrário das investidas contemporâneas em direção a uma concepção procedimental de democracia, entre as quais a mais notória é a de Habermas, a concepção de Dewey não é formalista e, muito menos, dogmática ${ }^{10}$.

Outro argumento que Dewey desenvolveu na década de 1930 e que recentemente vem sendo utilizado por Habermas e outros teóricos da democracia (tais como Joshua Cohen, Andrew Arato e Chantal Mouffe) - sem nenhuma menção, evidentemente, ao fato de que Dewey utilizou o termo antes - é a noção de democracia radical. Por essa idéia Dewey entendia o fato de que os meios e os fins da democracia são inevitavelmente inseparáveis. Ou seja, a democracia não é meramente um fim, mas também não se resume a um meio; ela é ao mesmo tempo meio e fim. Esses

\footnotetext{
10 É preciso mencionar que Habermas cita Dewey três vezes ao longo de todo o seu Between Facts and Norms, apesar de não se dar ao trabalho de agregar às referências nem mesmo uma breve análise do autor. Uma das alusões a Dewey, contudo, dá-se justamente no capítulo dedicado à democracia deliberativa, quando afirma que "ninguém trabalhou este ponto de vista mais energicamente do que John Dewey" (HABERMAS, 1996, p. 304). O "ponto de vista" a que se refere é que "o procedimento democrático é institucionalizado em discursos e processos de barganha pelo emprego de formas de comunicação que prometem que todos os resultados alcançados em conformidade com o procedimento serão razoáveis" (ibidem). Convenhamos que Dewey jamais falou em "processos de barganha" ou em qualquer coisa semelhante que possa indicar isso. $\mathrm{Pa}$ rece ser um pouco exagerado da parte de Habermas transformar a palavra "persuasão", que de fato Dewey emprega, em um processo de barganha. De todo modo, foi feita a referência ao fato de que Dewey tratou do assunto, coisa que muitos teóricos recentes da democracia deliberativa parecem ignorar. Resta faltando que algum deles aventure-se a estudar o pensamento de Dewey de maneira mais sistemática, de modo a conceder-lhe o seu devido lugar no início da estrada da democracia deliberativa.
} 
meios e fins podem ser de qualquer espécie, pois sempre haverá um meio de concretizar um fim. Assim, "não há nada mais radical do que a insistência sobre métodos democráticos como os meios pelos quais mudanças sociais radicais são efetuadas" (DEWEY, 1998 [1937], p. 339). Desse modo, afirma Dewey, não haveria oposição, por exemplo, em sustentar meios democráticos liberais combinados com fins que são socialmente radicais. "O fim da democracia é um fim radical. Pois é um fim que não tem sido adequadamente realizado em nenhum país em nenhum momento. Ele é radical porque requer uma grande mudança nas instituições sociais, econômicas, jurídicas e culturais existentes" (idem, p. 338-339).

O que faz que a concepção de democracia de Dewey possa combinar, ao mesmo tempo, mecanismos diretos e indiretos, participação e representação, deliberação e procedimento, liberalismo e radicalismo social, é justamente a sua expressão por meio da "idéia de democracia". Esta idéia, alternativamente adjetivada por Dewey e seus comentadores como sendo social, moral ou ética, não é nem forma nem substância, é algo ao mesmo tempo abstrato e concreto... é algo que, em um sentido bem pragmatista, ainda está - e sempre estará - sendo feito ("in the making"). Não existe, portanto, um princípio que expresse essa idéia, assim como não existe uma forma nem um conteúdo predeterminado e tampouco um ponto de chegada para ela ${ }^{11}$.

\section{A DEMOCRACIA COMO UM MODO DE VIDA}

A melhor maneira de compreender a idéia de democracia Dewey ofereceu-nos em um artigo escrito por ocasião da comemoração do seu aniversário de 80 anos (DEWEY, 1998 [1939], p. 340-343). Esse artigo, que certamente poderá permanecer por todo o resto da história democrática como um panfleto em prol da democracia, um belo e vivo manifesto pela democracia, reitera a crença de que a mesma não pode ser encarada meramente como um mecanismo político. A democracia, a "idéia", afinal, é um "modo de vida". Mas esse modo de vida não é qualquer um; ele não

11 Observe-se como as origens experimentalistas e hegelianas do pragmatismo são incontestáveis nesse conceito de "idéia de democracia" de Dewey. pode, por exemplo, ser imposto de fora nem ser derivado de nenhuma externalidade. Trata-se de um modo de vida pessoal, constituído por cada indivíduo. Para entender a idéia de democracia, portanto, é preciso perceber "[...] no pensamento e na ação que a democracia é um modo pessoal de vida individual; que ela significa a possessão e o uso contínuo de certas atitudes, formando o caráter pessoal e determinando o desejo e o propósito em todas as relações da vida. Ao invés de pensar em nossas próprias disposições e hábitos como acomodados a certas instituições, nós temos que aprender a pensar nestas últimas como expressões, projeções e extensões das atitudes pessoais habitualmente dominantes" (idem, p. 341; grifos no original).

Em conseqüência, a idéia de democracia não tem que se adaptar às instituições, sobretudo às instituições políticas, mas, ao contrário, são as instituições que têm que se adaptar não somente à democracia, mas também aos hábitos dos indivíduos - aos seus modos de vida. Em outras palavras - deweyanas, certamente -, a "democracia política" deve subordinar-se à "idéia de democracia".

Inevitavelmente associado à idéia de democracia como um modo de vida, está um outro conceito importantíssimo correlato à teoria democrática de Dewey: a fé. Evidentemente, não se está falando de qualquer fé. Trata-se de uma fé democrática, digamos assim. Essa fé deweyana, por sua vez, decerto expressa a mais interessante das crenças do seu autor, qual seja, a crença no "Homem Comum". "A democracia é um modo de vida comandado por uma operante fé nas possibilidades da natureza humana. A crença no Homem Comum é um artigo familiar do credo democrático. Essa crença não tem base nem significado senão quando significa fé nas potencialidades da natureza humana na medida em que essa natureza é exibida em todo ser humano sem distinção de raça, cor, sexo, nascimento e família, riqueza material ou cultural. Essa fé pode ser decretada em leis, mas ela será apenas papel a não ser que seja colocada em vigor nas atitudes que os seres humanos possuem uns com os outros em todos as circunstâncias e relações da vida cotidiana" (ibidem).

A democracia é, assim, um modo de vida pessoal comandado não apenas pela fé na natureza humana em geral, explica Dewey, mas pela fé na 
capacidade de os seres humanos terem discernimento (judgement) e uma ação inteligente. Estão em jogo aqui os conceitos pragmatistas de inteligência e criatividade. Alguns autores consideram que Dewey utiliza o conceito de inteligência muitas vezes como substitutivo da idéia de razão (BERNSTEIN, 1971, p. 222; WESTBROOK, 1991, p. 356-361; ALEXANDER, 1995, p. 138-142). No entanto, a inteligência é uma potencialidade de todos os seres humanos que, contudo, não se encontra plenamente desenvolvida sem a educação. Assim como a educação é essencial para a constituição da comunidade, ela é também essencial para a consolidação da democracia. Aliás, a prática da vida comunal e da democracia nela incluída é também, por sua vez, constitutiva do aprendizado e desse tipo de inteligência de que nos fala Dewey. "[...] O objetivo da educação é capacitar o indivíduo para continuar a sua educação - ou o objeto e a recompensa do aprendizado é a capacidade contínua de crescimento. No entanto, essa idéia não pode ser aplicada para todos os membros de uma sociedade exceto onde o intercurso do homem com o homem seja mútuo, exceto onde exista provisão adequada para a reconstrução dos hábitos e instituições sociais por meio de um amplo incentivo originado dos interesses eqüitativamente distribuídos. E isso significa uma sociedade democrática" (DEWEY, 1998 [1916], p. 250; grifo no original).

A capacidade da inteligência do homem comum para responder satisfatoriamente aos problemas sociais deve, em conseqüência, ser desenvolvida não apenas por meio da educação, mas também por meio da prática cotidiana do exercício da cidadania em uma sociedade democrática. $\mathrm{O}$ que propicia, contudo, que a inteligência seja desenvolvida tanto nas escolas como em outros lugares e momentos da vida associativa comunal é o livre exercício da comunicação. Em outras palavras, na medida em que os indivíduos passam a ter plena oportunidade de interagir, discutir e deliberar publicamente a respeito dos problemas que envolvem a sua comunidade, sua inteligência desenvolve-se. O que está em jogo nessa noção de inteligência, portanto, é também uma capacidade prática de lidar com os problemas efetivos que a sociedade real apresenta cotidianamente. E se a educação promovida pelas escolas contribui para isso ao constituir-se em um protótipo de comunidade, ela sozinha não basta - é preciso que ela possa ser estendida para as outras atividades e núcleos da vida associativa. É preciso que os indivíduos tenham oportunidade de aprender a pensar e a agir diante de todos os problemas da sua comunidade - do contrário, afinal, ela não seria uma comunidade democrática. A fé democrática, portanto, traduz-se na confiança nessa capacidade inesgotável do homem de responder aos problemas da sua comunidade por meio do exercício comunicativamente livre e prático de suas próprias respostas. "Pois o que é a fé na democracia nos papéis de consulta, de conferência, de persuasão, de discussão, na formação da opinião pública, a qual a longo prazo é autocorretiva, senão fé na capacidade de inteligência do homem comum para responder com bom senso ao livre jogo de fatos e idéias que são assegurados pelas garantias efetivas da livre investigação, da livre reunião e da livre comunicação?” (DEWEY, 1998 [1939], p. 342).

Dewey sabe perfeitamente que, no contexto de um processo tão livre, e tão intrinsecamente autocorretivo de intercomunicação, é inevitável que surjam conflitos entre os indivíduos, dado que cada um tem a sua própria maneira de enxergar necessidades, fins e conseqüências (afinal, a democracia é um modo pessoal de vida). A solução para tais conflitos é a "cooperação amigável" que, como nos esportes, pode incluir a rivalidade e a competição, porém não a força - que se exerce, no âmbito do debate e da inteligência, por meio da tentativa constante de aprender-se alguma coisa com aqueles de quem discordamos e, nessa medida, fazer deles amigos em potencial. Em outras palavras, as disputas e controvérsias devem ser transformadas em empreendimentos cooperativos em que as duas partes aprendem ao possibilitar, uma à outra, a chance de expressar-se. E essa chance deve ser conferida não porque consiste em um direito das pessoas, mas porque representa uma crença na expressão das diferenças, que, por sua vez, consiste em "um meio de enriquecer a experiência de vida pessoal de cada um" (ibidem).

\section{CONSIDERAÇÕES FINAIS}

Em conclusão, a democracia deweyana é um modo de viver que acredita na experiência simultaneamente como meio e como fim. Os processos e interações intercomunicativos servem, assim, para alargar e enriquecer essa experiência. A atualidade do pensamento de Dewey mostra como é possível pensar a partir de alguns dos conceitos mais atuais da Teoria Política contemporânea, tais 
como deliberação, procedimento e comunicação, sem, no entanto, precisar abrir mão de alguns dos conceitos centrais da matriz filosófica do pragmatismo, como é o caso do conceito de experiência ${ }^{12}$. É possível, portanto, e ao contrário do que pensam alguns neopragmatistas como Richard Rorty, elaborar uma teoria política genuinamente pragmatista sem deixar de lado o conceito filosófico de experiência - e, principalmente, sem precisar substituí-lo pela idéia de linguagem. Como vimos com Dewey, a comunicação é peça essencialmente necessária aos conceitos pragmatistas de comunidade e democracia. Mas ela não é suficiente. A comunicação só é relevante na medida em que é ela que possibilita que a experiência seja permanentemente ampliada, alargada, enriquecida e perpetuada. Diante disso, a comunicação é sempre secundária em face da experiência; ela é sempre um meio, enquanto a experiência é sempre, e ao mesmo tempo, meio e fim.

A democracia, afinal, não consiste em uma crença no potencial ainda não inteiramente conhecido da comunicação, mas consiste em uma crença nas múltiplas e infinitas potencialidades da experiência humana e da experiência social. Por conseguinte, a tarefa premente de recuperar uma teo-

12 Sobre a matriz filosófica do pragmatismo e seus pressupostos antifundacionalistas, contextualistas e consequencialistas, veja-se Pogrebinschi e Eisenberg (2002, p. $107-$ 110) e Pogrebinschi (2002, p. 8-65). ria política pragmatista é efetivamente uma tarefa de recuperação, no sentido de recriação. Não é preciso um neopragmatismo que pretenda meramente buscar na matriz filosófica do pragmatismo clássico elementos para construir uma nova teoria política pragmatista. O pragmatismo político de Dewey é ainda uma teoria política viva. Sua atualidade e sua vitalidade precisam ser conhecidas e, a partir disso, re-criadas. Eé nisso que deve residir a inteligência, a criatividade, dos novos pragmatistas $^{13}$.

\begin{abstract}
13 Há dois artigos recentes sobre a democracia deweyana que efetivamente apresentam uma recriação criativa dos argumentos de Dewey. Um deles é o do neopragmatista Hilary Putnam (1991, p. 217-246) que intenta encontrar em Dewey uma justificação epistemológica da democracia. O outro é de Robert Westbrook (1998, p. 128-140), que, de tanto estudar o pensamento de Dewey com lentes de historiador vem-se mostrando um verdadeiro neopragmatista, apto a discutir todos os seus aspectos políticos com uma qualidade que poucos apresentam. Vale atentar no início do artigo de Westbrook justamente para essa idéia de que o neopragmatismo, seja pelas mãos dele, de Rorty, de Putnam ou de qualquer outro que se aventure, consiste em uma re-criação do pragmatismo clássico, o que pode se dar de maneira mais ou menos fidedigna, literal, em cada um que tome para si tal tarefa.
\end{abstract}

Thamy Pogrebinschi (thamy@iuperj.br) é Doutoranda em Ciência Política no Instituto Universitário de Pesquisas do Rio de Janeiro (IUPERJ), autora dos livros Onde está a democracia?, com José Eisenberg (2002) e O problema da obediência em Thomas Hobbes (2003). Vencedora do Prêmio Associação Nacional de Pós-graduação em Ciências Sociais-Editora da Universidade do Sagrado Coração (ANPOCSEDUSC) 2002 na área de Ciência Política.

\section{REFERÊNCIAS BIBLIOGRÁFICAS}

ALEXANDER, T. 1995. John Dewey and the Roots of Democratic Imagination. In : LANGSDORF, L. \& SMITH, A. Recovering Pragmatism's Voice. Albany : State University of New York.

BERNSTEIN, R J. 1971. Praxis and Action. Philadelphia : University of Pennsylvania.
1998. Community in the Pragmatic Tradition. In : DICKSTEIN, M. The Revival of Pragmatism : New Essays on Social Thought, Law and Culture. Durham : Duke University.

BOHMAN, J. \& REHG, W. 1997a. Deliberative Democracy. Cambridge, Mass. : Massachusetts Institute of Technology. 
. 1997b. Introduction. In : BOHMAN, J. \& REHG, W. Deliberative Democracy. Cambridge, Mass. : Massachusetts Institute of Technology.

DEWEY, J. 1927. The Public and Its Problems. Chicago : Swallow.

1998 [1916]. Aims in Education. In : HICKMAN, L. \& ALEXANDER, T. The Essential Dewey. V. I : Pragmatism, Education, Democracy. Bloomington : Indiana University.

1998 [1919]. Philosophy and Democracy. In : HICKMAN, L. \& ALEXANDER, T. The Essential Dewey. V. I : Pragmatism, Education, Democracy. Bloomington : Indiana University. 1998 [1937]. Democracy Is Radical. In : HICKMAN, L. \& ALEXANDER, T. The Essential Dewey. V. I : Pragmatism, Education, Democracy. Bloomington : Indiana University. . 1998 [1939]. Creative Democracy - The Task Before Us. In : HICKMAN, L. \& ALEXANDER, T. The Essential Dewey. V. I : Pragmatism, Education, Democracy. Bloomington : Indiana University.

FESTENSTEIN, M. 1997. Pragmatism and Political Theory. Chicago : University of Chicago.

HABERMAS, J. 1996. Between Facts and Norms. Cambridge, Mass. : Massachusetts Institute of Technology.

HICKMAN, L. \& ALEXANDER, T. 1998. The Essential Dewey. V. I : Pragmatism, Education, Democracy. Bloomington : Indiana University.

LIPPMANN, W. 1993 [1925]. The Phanton Public. New York : Transaction.
1997 [1922]. Public Opinion. New York : Free Press.

POGREBINSCHI, T. 2002. A teoria social e política do Pragmatismo. Rio de Janeiro. Dissertação (Mestrado em Ciência Política). Instituto Universitário de Pesquisas do Rio de Janeiro.

2003. O problema da obediência em Thomas Hobbes. Bauru : USC.

POGREBINSCHI, T. \& EISENBERG, J. 2002a. Pragmatismo, Direito e política. Novos Estudos CEBRAP, São Paulo, n. 62, p. 107-121, mar.

2002b. Onde está a democracia? Belo Horizonte : UFMG.

PUTNAM, H. 1991. A Reconsideration of Deweyan Democracy. In : BRINT, M. \& WEAVER, W. Pragmatism in Law and Society. San Francisco : Westview.

RYAN, A. 1995. John Dewey and the High Tide of American Liberalism. New York : W. W. Norton.

WALLAS, G. 1914. The Great Society : A Psychological Analysis. New York : Macmillan.

WESTBROOK, R. 1991. John Dewey and American Democracy. Ithaca : Cornell University.

1998. Pragmatism and Democracy : Reconstructing the Logic of John Dewey's Faith. In : DICKSTEIN, M. (ed.). The Revival of Pragmatism: New Essays on Social Thought, Law and Culture. Durham : Duke University. 